\title{
Gullies and debris flows analysis: a case study in Sardinia and a rheological modelling approach
}

\author{
A. $\mathrm{Canu}^{1} \&$ G. Lorenzini ${ }^{2}$ \\ ${ }^{I}$ CNR-IBIMET, Institute of Biometeorology, Sassari, Italy \\ ${ }^{2}$ Department of Agricultural Economics and Engineering, \\ Alma Mater Studiorum-University of Bologna, Italy
}

\begin{abstract}
Soil erosion is one of the main causes of desertification in the Mediterranean basin. Recently, the role of channelled erosion in sediment delivery has been underlined by several studies. Rheological studies of debris flows, which provide information on the properties of the mixture, are essential for improving prediction and designing mitigation for potential hazardous areas. The paper has two aims: describing a simplified experimental methodology, set up for studying the relationships between Gully erosion and land use, applied to an experimental hilly site threatened by desertification in Central Eastern Sardinia (Italy); showing a debris flow model, based on a dimensional analysis and calibrated with experimental data, to identify the causes for momentum transport in the process. The results show a very significant impact of agricultural activities on Gully intensity and density, while the debris flow model proves to be capable of satisfactory predictions of actual events.
\end{abstract}

Keywords: Gullies, debris flows, desertification, land use, momentum transport.

\section{Introduction}

The soil being eroded by the water is, in the Mediterranean area, one of the most important land degradation processes. Despite Gully erosion being a significant sediment source which aggravates off-site effects of water erosion [1, 2], literature has mainly focused on rill and interrill erosion, as Gully-related in-field activities are very challenging [3]. It is then fundamental to monitor, experiment and model how the environment is affected by Gully erosion. Under the latter 
aspect, Sardinia is representative of many Mediterranean rural areas: in particular, its agropastoral activity is the main land degradation cause, especially since a lot of its Mediterranean maquis is being eliminated for the creation of new pastures [4,5], making soil erosion an ever increasing and diffused phenomenon. Related to the same topic of land use and environmental control, Mud and debris flows are mixtures of water and sediment which can, under certain conditions, produce destructive flows that contribute to the growth of alluvial fans in mountainous areas. This enhances the hazards linked to debris flows, making it urgent to map risky areas and to implement mitigation [6]. debris flows typically transform a solid mass into a fluid mixed with water: both components cause energy dissipation and momentum transfer from the core of the flow to the boundary [7]. The key problem is so which terms in the constitutive equation best represent the behaviour of these mixtures even if, in actual events, a continuum system is what generally can be found [6]. The present work, split in two parts, has two main purposes: applying a simplified experimental approach to deepen the mutual affections among Gully erosion, land types and land use; showing an analytical application to debris flow rheology. The first aim was achieved thanks to an in-field activity made in an agropastoral environment subjected to high anthropic pressure, while the second was made possible thanks to a dimensional analysis technique and without neglecting any visco-plastic-collisional contribution. The results show, on the one hand, an extremely elevate affection of Gully intensity and location by the agricultural activities; on the other prove how debris flow in-field events can be suitably described using the approach proposed.

\section{Gully analysis}

\subsection{Activities and data analysis}

Gully channels were surveyed. In order to characterise each Gully site, several parameters were recorded on the field in May 2004. The position and altitude of each channel head was measured with a GPS. The observed substrata were: Colluvial deposits (D), Coarse-grained tonalithic granodiorites (Gg), Compact microcristalline granites $(\mathrm{Gm})$, Metamorphites, low metamorphic degree (M). Following a well tested methodology $[2,8,9]$, length, width and depth of Gullies were measured. The channels were split up in uniform segments of variable length but characterised by approximately constant cross-sectional shape. The average slope of the Gully bed along each segment was also measured. Channels volume was evaluated by multiplying the length of each segment by the average section [2, 3, 8, 9]. Data analysis was mainly focused on: length-volume relationship, Gullies morphology and Gullies frequency, calculation of the topographical threshold. As reported by Nachtergaele et al. [10], length value can be used to estimate indirectly the volume, and a positive correlation between length and volume can be expressed through the following equation:

$$
\mathrm{V}=a \mathrm{~L}^{b}
$$

where $\mathrm{V}=$ Gully volume $\left(\mathrm{m}^{3}\right)$ and $\mathrm{L}=$ Gully length (m). Equation (1) was used to calculate the $a$ and $b$ coefficient values obtained for the study area that were 
then compared with the values reported by other authors. The morphological aspects of Gullies selected for analysis were: mean length, mean volume and mean width/depth ratio. Terrain types, geological substratum and slope were considered. The map of land use historical dynamics was used to highlight the effects of the anthropic pressure on Gullies formation. Starting from the available maps for slope, and land use history (new pastures created in different periods), the occurrence and spatial frequency of Gullies was estimated for each map unit. That was done through ArcView software and with reference to the following Gully frequency indicators ( $A$ is the area of the map unit): N/A (N: number of Gullies within the map unit); L/A (L: cumulated length of the Gullies within the map unit); V/A (V: cumulated volume of the Gullies within the map unit). The prediction of the channel head location is an essential component of theories of channel network growth. Channel initiation is controlled by a variety of processes which may be modelled as threshold phenomena. The analytical models for channel initiation provided by different authors, involve relations between contributing drainage area $(A)$ and local slope $(S)$ at the channel head $[11,12,13,14,15]$. In this study the following equation, reported by Vandaele et al. [13] and Begin and Schumm [16], was used:

$$
S=a A^{-b}
$$

where $S=$ local slope ( $\mathrm{m} \mathrm{m}^{-1}$ ) and $A=$ contributing drainage area (ha). Equation (2) may be written as follows: $S A^{b}=a$, where $a$ represents the threshold value for the Gully erosion initiation. According to this model, whenever $S A^{b} \geq a$ the Gully erosion will take place.

Table 1: Gully parameters. SD: Standard Dev.; CV: Coeff. of variation.

\begin{tabular}{lccccccc}
\hline & Total & Min & Max & Average & SD & CV (\%) Specific* \\
\hline Slope $(\%)$ & & 4.7 & 63.5 & 23.9 & 12.8 & 53.5 & \\
Length (m) & 1740.5 & 8.5 & 224.0 & 54.4 & 51.2 & 94.2 & 2.4 \\
Mean width (m) & & 0.30 & 2.13 & 0.96 & 0.44 & 45.7 & \\
Mean depth (m) & 0.16 & 0.91 & 0.44 & 0.19 & 42.7 & \\
Eroded area $\left(\mathrm{m}^{2}\right)$ & 1813.1 & 6.8 & 280.0 & 56.7 & 64.9 & 114.6 & 2.5 \\
Eroded volume $\left(\mathrm{m}^{3}\right)$ & 972.6 & 1.2 & 211.5 & 30.4 & 44.6 & 146.9 & 1.3 \\
\hline
\end{tabular}

* per surface unit (ha)

\subsection{Results}

A total of 32 Gullies were measured in the study area. Table 1 reports statistics for the recorded parameters. In figure a, a log-log graph reporting the values of length and volume of the Gullies along with the regression line (equation 1) is shown. In the equation (1) the value of the exponent $b$ is greater than 1 ; this is due to the fact that the cross sectional area of long Gullies is greater than those of shorter ones, as observed in the field. The field observations revealed that the shape of Gullies is mainly controlled by the geological substratum. The main difference was observed between soils developed on the two main substrata: coarse granites and colluvial deposits. 
Figure $1 \mathrm{~b}$ shows the mean Gully volume with reference to different geological substrata. Again, it is possible to appreciate that on colluvial deposits the mean volume is definitely higher, due to the more elevated erodibility in relation to the concentrated flow. On colluvial deposits the channels get deeper and wider, whereas on granites they show a tendency to be shallow and with a smaller cross-sectional area. With reference to slope class, the maximum number of Gullies (24) was recorded on slope ranging from 15 to $55 \%$ (table 2). Looking at the Gully frequency indexes, a positive trend is evident as far as all indexes increase with slope, except for the fourth class (25-55\%). The low values might be due to the shallower soils and reduced slope lengths that generally characterise the steeper slopes in this area. The fifth slope class, that affects only 9.88 ha $(1.3 \%$ ), shows very high values for N/A, L/A and V/A but it includes only 2 Gullies.

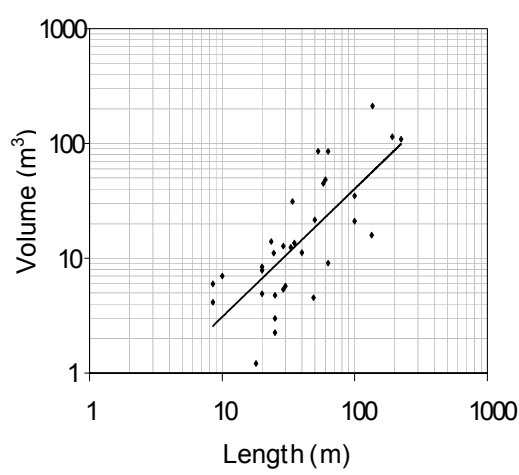

(a)

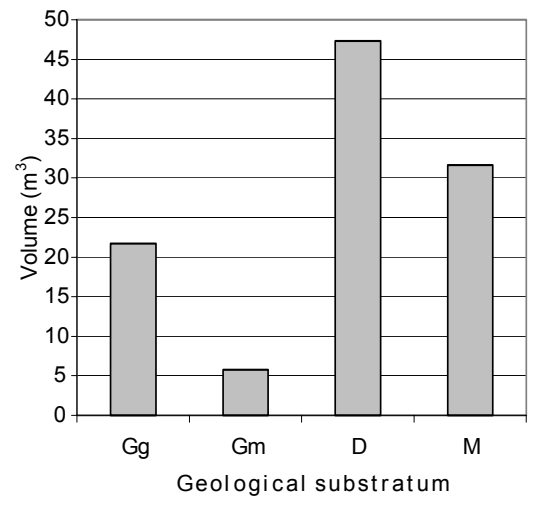

(b)

Figure 1: (a) Relationship length-volume. Regress. eq.: $\mathrm{y}=0.235 \mathrm{x}^{1.12}$ $\left(\mathrm{R}^{2}=0.55 ; \mathrm{n}=32\right.$ ); (b) Mean volume of the Gullies grouped by geological substratum (D: Colluvial deposits; Gg: Coarse-grained tonalithic granodiorites; $\mathrm{Gm}$ : Compact microcristalline granites; M: Metamorphites).

Table 2: $\quad$ Gully erosion frequency indexes and mean values (slope class).

\begin{tabular}{ccccccccc}
\hline $\begin{array}{c}\text { Slope } \\
(\%)\end{array}$ & $\begin{array}{c}\mathrm{A} \\
(\mathrm{ha})\end{array}$ & $\mathrm{N}$ & $\mathrm{N} / \mathrm{A}$ & $\begin{array}{c}\mathrm{L} \\
(\mathrm{m})\end{array}$ & $\begin{array}{c}\mathrm{L} / \mathrm{A} \\
\left(\mathrm{m} \mathrm{ha}^{-1}\right)\end{array}$ & $\begin{array}{c}\mathrm{V} \\
\left(\mathrm{m}^{3}\right)\end{array}$ & $\begin{array}{c}\mathrm{V} / \mathrm{A} \\
\left(\mathrm{m}^{3} \mathrm{ha}^{-1}\right)\end{array}$ & $(\mathrm{w} / \mathrm{d})_{\mathrm{m}}$ \\
\hline $0-6$ & 91.92 & 2 & 0.022 & 113 & 1.23 & 133.19 & 1.45 & 3.34 \\
$6-15$ & 137.80 & 4 & 0.029 & 523 & 3.86 & 243.14 & 1.76 & 1.76 \\
$15-25$ & 156.79 & 12 & 0.077 & 615 & 3.92 & 429.20 & 2.74 & 2.57 \\
$25-55$ & 322.76 & 12 & 0.037 & 359 & 1.11 & 123.74 & 0.38 & 2.83 \\
$>55$ & 9.88 & 2 & 0.202 & 150 & 15.18 & 42.57 & 4.31 & 3.15 \\
\hline
\end{tabular}

A: area of the map unit; N: number of Gullies; L: cumulated Gullies length; $\mathrm{V}$ : cumulated Gullies volume; $(\mathrm{w} / \mathrm{d})_{\mathrm{m}}$ : mean width/depth ratio.

The results obtained for different land use history classes are shown in table 3. The indicators N/A and L/A are very high for class A, that represents the 
pastures more recently created. These pastures are often located on non-suitable lands. However V/A values are higher for class $\mathrm{D}$, that represents pastures created between 1955 and 1977, and thus subdued to a longer pressure. No Gullies have been found in class E, that represents the first pastures created before 1955, probably because those pastures are mainly situated on very suitable lands.

Table 3: Gully erosion frequency indexes and mean values, historical data. A: 1991 to 1997 ; B: 1989 to 1991 ; C: 1977 to 1989 ; D: 1955 to 1977; E: before 1955.

\begin{tabular}{ccccccccc}
\hline $\begin{array}{c}\text { Land use } \\
\text { history class }\end{array}$ & $\begin{array}{c}\mathrm{A} \\
(\mathrm{ha})\end{array}$ & $\mathrm{N}$ & $\mathrm{N} / \mathrm{A}$ & $\begin{array}{c}\mathrm{L} \\
(\mathrm{m})\end{array}$ & $\begin{array}{c}\mathrm{L} / \mathrm{A} \\
\left(\mathrm{m} \mathrm{ha}^{-1}\right)\end{array}$ & $\begin{array}{c}\mathrm{V} \\
\left(\mathrm{m}^{3}\right)\end{array}$ & $\begin{array}{c}\mathrm{V} / \mathrm{A} \\
\left(\mathrm{m}^{3} \mathrm{ha}^{-1}\right)\end{array}$ & $(\mathrm{w} / \mathrm{d})_{\mathrm{m}}$ \\
\hline A & 9.56 & 2 & 0.209 & 67 & 7.01 & 5.76 & 0.60 & 2.96 \\
B & 44.06 & 2 & 0.045 & 66.5 & 1.51 & 49.11 & 1.11 & 2.32 \\
C & 420.15 & 16 & 0.038 & 748 & 1.78 & 185.49 & 0.44 & 2.75 \\
D & 213.78 & 12 & 0.056 & 887.5 & 4.15 & 731.48 & 3.42 & 2.52 \\
E & 33.07 & - & - & - & - & - & - & - \\
\hline
\end{tabular}

A: area of the map unit; N: number of Gullies; L: cumulated Gullies length; $\mathrm{V}$ : cumulated Gullies volume; $(\mathrm{w} / \mathrm{d})_{\mathrm{m}}$ : mean width/depth ratio.

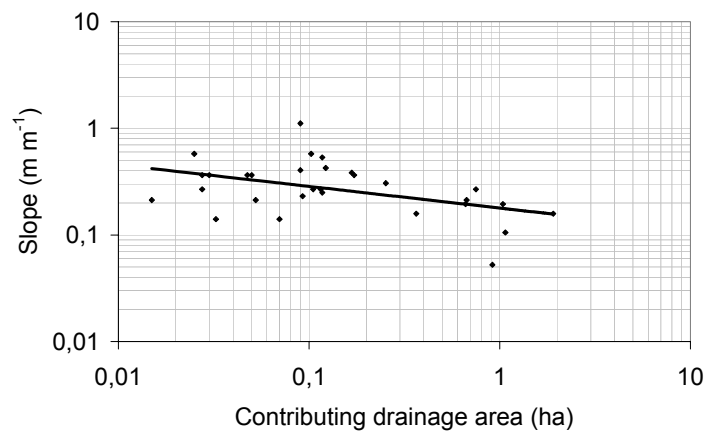

Figure 2: Contributing drainage area and local slope at the Gully head.

Figure 2 (regression equation: $y=0.179 x^{-0.20}, R^{2}=0.20 ; n=30$ ) shows a loglog graph representing the relationship between critical slope of soil surface and the contributing drainage area at the Gully head. The regression line (equation 2) is also plotted. The obtained coefficients are similar to those reported by other authors for Mediterranean study area [17], however they are not completely consistent with the theoretical model because the $b$ value is significantly lower. The reasons why $b$ is lower for this kind of soil are not completely explained yet, but many of the authors cited by Vandekerckhove et al. [17] stated that a subsurface flow may take place, as the stones help the water infiltration and the bedrock acts as a table on which the water can flow. As the equation 2 is based only on the overland flow processes, it cannot give a correct prediction when subsurface flow processes are involved. 


\section{Debris flow analysis}

\subsection{The problem}

Achieving a set of debris flow constitutive equations is a task which has been given particular attention $[18,19,20]$. Six debris flow regimes were classified [21]: friction, collisional, friction-collisional, macro-viscous, visco-plastic and visco-plastic-collisional. On the latter, involving all the key resistive shear stresses, mainly focuses the recent studies on debris flow mechanics [6]. The Dispersive Model [22, 23], that also accounts for the normal stress which causes dilatation in the material, considers the dispersive stress, arising from particle collision, to be dominant. So, if the interstitial fluid is particularly dense, large clastic rocks can appear to float near the surface due to buoyancy and dispersive stress. Another approach [24], based on Coulomb's viscous model, considers the viscous stress of the interstitial fluid to be dominant and ignores granular interactions. Two important rheological models have been proposed for the visco-plastic-collisional regime: Julien and O'Brien's [18] Quadratic Model, which linearly combines stresses linked to cohesion, viscous interaction, collisions and turbulence; Chen's [19] Generalised Viscoplastic Fluid model (GVF), which contains both an independent term and one that is dependent on the shear rate, but excludes the viscous shear stress term. A uniformly featured debris flow shows a monotonic or not velocity profile in theoretical or actual cases, respectively. The velocity profile of a debris flow with uniform features shows discrepancies between theoretical (monotonic trend) and actual data (inflexion points often present). Mixed-layer models were so defined: among them, Takahashi's Unified Model of the Inertial debris flow [20] hypothesises the flow as a lower collisional layer and an upper turbulent one with different constitutive equations, for which is crucial the dependence of the rheological coefficients on the sediment concentration and on the distribution of static pressure. Treating the debris flow as a non-uniform mixture requires also a diffusion equation: alas, little data is available on the diffusion mechanism $[6,21]$.

\subsection{Models}

The previous section showed the need of different rheological models in different flow regions, possibly without neglecting all the potential shear stresses. Bagnold's model [23] tries to avoid empiricism focusing on shear rate. The debris flow velocity distribution for various concentrations can be computed considering viscous and turbulent effects: Mixed-Layer models, in which the mixing due to vertical turbulences leads to uncertainties in defining the thickness of the layers, become too complex. Within this context, Jan and Shen [21] believe that the Quadratic Model by Julien and O'Brien [18] is currently the best interpretative formula of debris flow mechanics, as it considers all the possible shear stresses, although its original formulation does not immediately lead to a solution for the flow field. Based on Julien and O'Brien's rheological model, an analytic quadratic approach for steady conditions was presented and validated $[25,26,27,28]$. It is based on the observation that the flow has a layer close to 
the bed subject to deformation and an upper layer (plug flow) which is relatively un-deformed. Within the plug flow, the fluid shear stress is less than the resistive yield stress, and no deformation occurs. The model describes the fluid behaviour of water-sediment mixtures in various regimes for the case where sediments are uniformly distributed throughout the depth of the flow. To find an analytical solution to the flow field, in case of uniform and steady flow in open channels (shear flow), taking into account the momentum conservation equation in the direction of the main flow, the model's equation is:

$$
\tau_{c}+p_{s} \tan \phi+C_{\mu}(d u / d z)+\left(C_{c}+C_{t}\right) \cdot(d u / d z)^{2}=\int_{z}^{h}\left[\left(\rho_{s}-\rho_{f}\right) C+\rho_{f}\right] g \sin \theta \cdot d z
$$

The solution is $\left(\mathrm{A}=4 \zeta \rho_{m} g \sin \theta / \mu_{d}^{2} ; \mathrm{B}=\mu_{d} / 2 \zeta\right)$ :

$$
\begin{array}{ll}
u(z)=-B z+\frac{2 B\left(1+A h_{p}\right)^{3 / 2}}{3 A}\left[1-\left(1-\frac{A}{1+A h_{p}} z\right)^{3 / 2}\right] & \text { for } 0 \leq \mathrm{z} \leq h_{p} \\
u_{p}=-B h_{p}+\frac{2 B\left(1+A h_{p}\right)^{3 / 2}}{3 A}\left[1-\frac{1}{\left(1+A h_{p}\right)^{3 / 2}}\right] . & \text { for } h_{p} \leq \mathrm{z} \leq h
\end{array}
$$

with these boundary conditions: $\mathrm{u}=0$ for $\mathrm{z}=0, \mathrm{u}=u_{p}$ and $\mathrm{du} / \mathrm{dz}=0$ for $\mathrm{z}=h_{p}$ $\left(h_{P}\right.$ is the co-ordinate perpendicular to the direction of the main flow, measured from the bed to the point in the flow in which stress equals yield stress, $u_{P}=u\left(h_{p}\right)$ ). The mean velocity comes integrating the expression between $\mathrm{z}$ and $h$, dividing by $h$ :

$$
\bar{U}=-\frac{B h}{2}\left(\frac{h_{p}}{h}\right)^{2}+\frac{2 B\left(1+A h_{p}\right)^{3 / 2}}{3 A}\left\{\frac{h_{p}}{h}+\frac{2}{5 A h}\left[\left(1+A h_{p}\right)^{-3 / 2}-\left(1+A h_{p}\right)\right]\right\} .
$$

\subsection{Dimensional analysis applied to debris flows}

The identification of dimensionless characteristic parameters was crucial to the approach [26]. The method employed is based on those in [7, 29]. $N_{3}=g / \dot{\gamma}^{2} d$, ratio of the granular mass weight to the dispersive force, was first identified by Savage [29] as $N_{S A V}=1 / N_{3}$. Based on experimental evidence, Savage and Hutter [30] concluded that dispersive stresses dominated the frictional resistance if $N_{S A V}>0.1 . N_{4}=\mu_{d} /\left(\dot{\gamma} d^{2} \rho_{s}\right)$, ratio between the viscous and dispersive force, was first proposed as $N_{B A G}=\lambda^{1 / 2} / N_{4}$ by Bagnold [23], who demonstrated that in a mixture of water and spherical sediments of equal density $\left(N_{S A V}=\infty\right)$ dispersive stresses dominate the viscous ones if $N_{B A G}>450$. The ratio between $N_{B A G}$ and $N_{S A V}$ gives the friction number [7] thus representing the frictional forces compared to the viscous forces. Iverson's experimental data [7] show a prevalence of friction force over viscous force for values $>1000-2000$. The dimensionless approach was then applied to experimental data to calculate the flow regimes and stress mechanisms acting in those cases: the laboratory works by Smart and Jaeggi [31], Lanzoni and Tubino [32], Gregoretti and Di Silvio 
[33], Davies [34]; the in-field events in the Chinese basin of Jiang-Jia Gully [35] and in the Italian basin of Acquabona [36] (see Tab. 4). This choice allowed one to verify if the analysis can match true data.

Table 4: $\quad$ Maximum and minimum values for Savage, Bagnold and friction numbers computed for laboratory and field data.

\begin{tabular}{|l|l|l|l|l|}
\hline \multicolumn{2}{|c|}{} & $N_{S A V}$ & $N_{B A G}$ & $N_{F R I}$ \\
\hline \multirow{2}{*}{ SMART-JAEGGI I } & Max & 0.249179 & 840.0229 & 4349.568 \\
\cline { 2 - 5 } & Min & 0.029028 & 108.0893 & 1425.899 \\
\hline \multirow{2}{*}{ LANZONI } & Max & 0.034755 & 68.82573 & 24713.08 \\
\cline { 2 - 5 } & Min & 0.00062 & 7.549037 & 1799.918 \\
\hline \multirow{2}{*}{ DREGORETTI } & Max & 0.15118 & 1039.925 & 33778.36 \\
\cline { 2 - 5 } & Min & 0.000643 & 7.351861 & 4095.018 \\
\hline \multirow{2}{*}{ ACQUABONA } & Max & 0.00898 & 0.852543 & 7975.078 \\
\cline { 2 - 5 } & Min & $2.84 \mathrm{E}-06$ & 0.006543 & 94.27352 \\
\hline \multirow{2}{*}{ CHINA } & Min & $8.98 \mathrm{E}-06$ & 0.041915 & $5.17 \mathrm{E}+08$ \\
\hline & Max & 0.012481 & 1.392489 & 23564.62 \\
\cline { 2 - 5 } & Min & $1.69 \mathrm{E}-06$ & 0.023519 & 108.2859 \\
\hline
\end{tabular}

In $[31,33]$ dispersive stress dominates over viscous stress when $N_{B A G}>450$, even if $[31,32,33]$ laboratory results were mainly characterised by dispersive and rate-independent stresses. Other experimental tests [34] were characterised by turbulent and viscous stresses. The dimensionless analysis applied to the real field events at Acquabona and Jiang-Jia Gully showed how friction played a predominant role but still to be studied. These experiments provided an effective calibration to the rheological model.

\subsection{Comparisons between experimental and theoretical results}

The predictive capability of the quadratic model was tested with available experimental and field data, as Fig. 3 shows, using homogeneous data groups to work with a statistical significance, also in relation to Fisher's LSD test. In addition to the two groups of field data $[6,36]$, two additional homogenous groups of data were obtained: the data in [32, 33] (first group) and in [31, 34] (second). The results (Figure 3), focused on mean flow velocity, show good agreement between observed and calculated values for the entire interval of slopes/regimes examined. This result is confirmed by an $\mathrm{R}^{2}$ always g.t. 0.85 . Actually, a slight dispersion around the identity line is present with respect to the comparative cases of [31] (slopes of $15 \%$ and $20 \% ; \mathrm{R}^{2}=0.57$ and $\mathrm{R}^{2}=0.59$ ) and of [21] (slopes $31 \% \div 35 \% ; \mathrm{R}^{2}=0.80$ ). This could be due to the substantial underestimation of solid material transport in current layers nearest to the bed, arising from the assumption of a debris flow as a uniform mixture, which could also be far wrong because of the gravity inside the mixture [22]. 


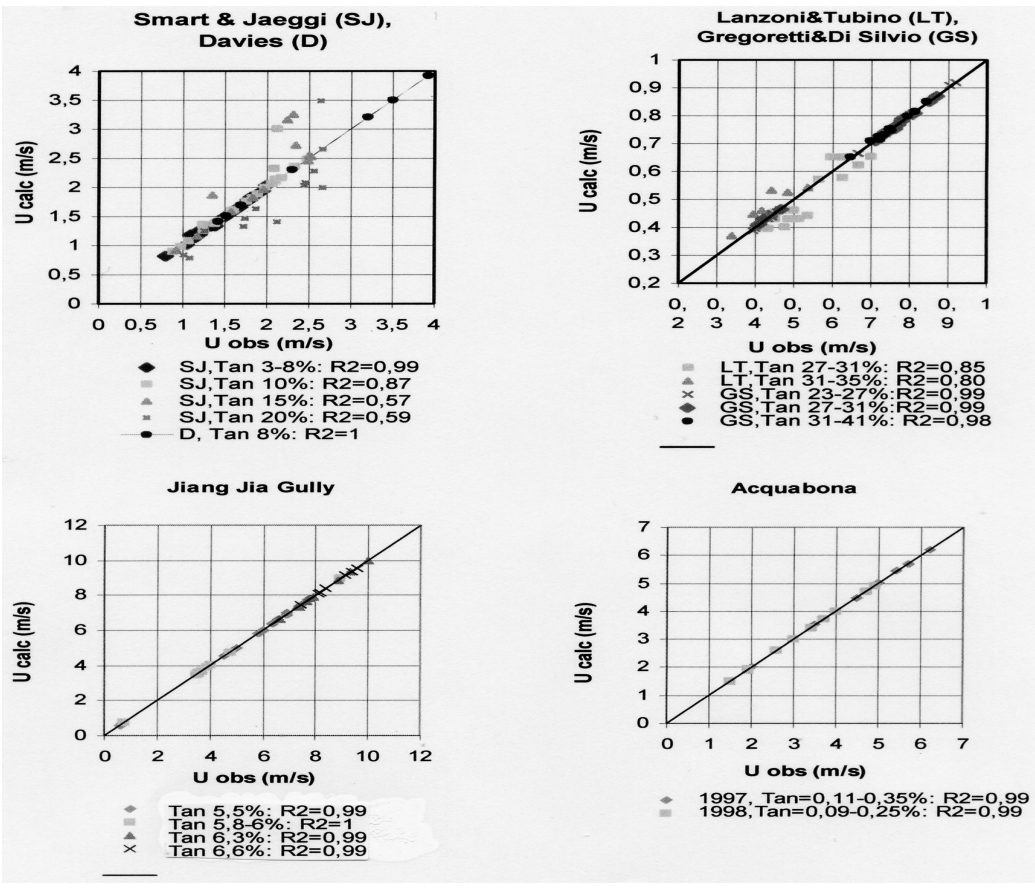

Figure 3: Mean velocity: comparing theoretical and experimental results.

The comparisons made, also allowed the verification of the model's assumption that the debris flow velocity can be estimated hypothesising a plug flow in its superficial portion. Figure 3 shows that this approach is the most rational for determining the velocity characteristics of a debris flow, even for scarcely cohesive laboratory currents $([31,32,33])$. These tests also illustrate that, ignoring the viscous forces due to water-granular material interactions, one is likely to overestimate the velocity of the current. Lastly, the fact that the agreement between calculated and observed data is better for in-field events than for laboratory ones, underlines the excellent explanatory and forecasting capacities of this rheological approach.

\section{Conclusions}

The present study faced two distinct but related problems: Gullies and debris flows. The results on the first aspect, studied by experimental means in Sardinia (Italy), where removing natural vegetation cover is presently causing severe soil erosion phenomena, confirmed what obtained in previous thematic studies, highlighting the role of agropastoral activities in Gully erosion initiation and development and confirming that Gullies spatial occurrence and frequency are mainly controlled by the geological substratum and by the slope angle; on the second aspect, instead, the consideration that momentum transport in a debris flow is characterised by the simultaneous presence of the forces of friction, viscosity, dispersion and turbulence, led the authors to the choice of a quadratic 
approach as well descriptive of those dynamics contributions, obtaining results which well agree with the experimental (in-field and laboratory) data available, especially for in-field events. Future studies on Gullies will extend the monitoring approach to different land systems, by the use of specific data, while future studies on debris flows will investigate the case of non-uniform solid concentration and non-steady flow conditions.

\section{Notation}

$A\left(\mathrm{~m}^{-5}\right), \mathrm{B}\left(\mathrm{s}^{-1} \mathrm{~m}^{2}\right)$, constants.

$C$, solid concentration.

$d(\mathrm{~m})$, diameter of the particles.

$\mathrm{g}\left(\mathrm{m} \mathrm{s}^{-2}\right)$, acceler. of gravity.

$h(\mathrm{~m})$, flow depth.

$\mathrm{p}(\mathrm{Pa})$, pressure.

$u\left(\mathrm{~m} \mathrm{~s}^{-1}\right)$, velocity (main flow direct.).

$z(\mathrm{~m})$, perpendic. dir. to main flow.

$\zeta\left(\mathrm{kg} \mathrm{m}^{-1}\right)$, dispersive-turbul. param.

$\theta\left({ }^{\circ}\right)$, inclination of the slope.

$\sigma(\mathrm{Pa})$, normal stress.

$\tau(\mathrm{Pa})$, shear stress.

$\phi\left(^{\circ}\right)$, angle of internal friction.

$\mathrm{C}_{\mu},\left(\mathrm{kg} \mathrm{m}^{-1} \mathrm{~s}^{-1}\right)$, viscous param.

$\mathrm{C}_{\mathrm{c}},\left(\mathrm{kg} \mathrm{m}^{-1}\right)$, collisional param.

$\mathrm{C}_{\mathrm{t}}\left(\mathrm{kg} \mathrm{m}^{-1}\right)$, turbulent parameter.

$N_{i(i=1, . ., 7)}$, dimensionless groupings.

$N_{F R I}$, friction number.
$N_{B A G}$, Bagnold number.

$N_{S A V}$, Savage number.

$R^{2}$ or R2, coeff. of determination.

$\bar{U}\left(\mathrm{~m} \mathrm{~s}^{-1}\right)$, mean $u$ value.

$\mathrm{U}_{\text {calc }}\left(\mathrm{m} \mathrm{s}^{-1}\right)$, mean veloc. calculated.

$\mathrm{U}_{\mathrm{obs}}\left(\mathrm{m} \mathrm{s}^{-1}\right)$, mean velocity observed.

$\mathrm{p}_{\mathrm{s}}(\mathrm{Pa})$, intergranular pressure.

$u_{p}\left(\mathrm{~m} \mathrm{~s}^{-1}\right)$, maximum $u$ value.

$\dot{\gamma}\left(\mathrm{s}^{-1}\right)$, shear rate.

$\lambda$, linear concentration.

$\mu_{d}$ (Pa s), dynamic viscosity.

$\rho_{f}\left(\mathrm{~kg} \mathrm{~m}^{-3}\right)$, fluid density.

$\rho_{m}\left(\mathrm{~kg} \mathrm{~m}^{-3}\right)$, mixture density.

$\rho_{\mathrm{s}}\left(\mathrm{kg} \mathrm{m}^{-3}\right)$, solid density.

$\tau_{c}(\mathrm{~Pa})$, cohesive stress.

$\tau_{y}(\mathrm{~Pa})$, yield stress.

\section{References}

[1] Vandekerckhove, L., Poesen, J., Oostwoud Wijdenes, D., de Figueiredo, T., Topographical thresholds for ephemeral Gully initiation in intensively cultivated areas of the Mediterranean. Catena, 33, pp. 271-292, 1998.

[2] Valcárcel, M., Taboada, M.T., Paz, A., Dafonte, J., Ephemeral Gully erosion in northwestern Spain. Catena, 50, pp. 199-216, 2003.

[3] Capra, A., Scicolone, B., Ephemeral Gully Erosion in a Wheat-cultivated Area in Sicily (Italy). Biosystem Engineering 83 (1), pp. 119-126, 2002.

[4] D’Angelo, M., Enne, G., Madrau, S., Zucca, C., Land cover changes at landscape-scale in Sardinia (Italy): the role of agricultural policies on land degradation. In: Conacher, A. (ed.), Land Degradation. Kluwer Academic Publishers. Dordrecht, The Netherlands. ISBN 0-7923-6770-7. pp. 127140, 2001.

[5] Zucca, C., Canu, A., Della Peruta, R., Spatial distribution and morphological features of Gullies in an agropastoral area in Sardinia (Italy). Proc. $3^{\text {rd }}$ International Conference on Gully Erosion Oxford (Mississippi), April 28-May 1, 2004. 
[6] Lorenzini, G., Mazza, N., Debris Flow: phenomenology and rheological modellisation", ISBN 1 - 85312 - 802 - 3, WIT Press (UK), 2004.

[7] Iverson, R. M., The physics of Debris Flows. Reviews of Geophysics, 35(3), pp. 245-296, 1997.

[8] Govers, G., Spatial and temporal variability in rill development processes at the Huldenberg experimental field. In: Bryan, R. K. (ed.), Rill Erosion: Processes and Significance. Catena Supplement, 8, pp. 35-54, 1987.

[9] Ludwig, B., Boiffin, J., Chadoeuf, J., Auzet, A.V., Hydrological structure and erosion damage caused by concentrated flow in cultivated catchments. Catena, 25, pp. 227-252, 1995.

[10] Nachtergaele, J., Poesen, J., Steegen, A., Takken, I., Beuselinck, L., Vandekerckhove, L., Govers, G., The value of a physically based model versus an empirical approach in the prediction of ephemeral Gully erosion for loess-derived soils. Geomorphology, 40, pp. 237-252, 2001.

[11] Patton, P.C., Schumm, S.A., Gully erosion, northern Colorado: A threshold phenomenon. Geology, 3, pp. 83-90, 1975.

[12] Montgomery, D.R., Dietrich, W.E., Landscape dissection and drainage area-slope threshold. In: Kirkby, M.J. (ed.), Process Models and Theoretical Geomorphology. Wiley, Chichester, UK, pp. 221-245, 1994.

[13] Vandaele, K., Poesen, J., Govers, G., van Wesemael, B., Geomorphic threshold conditions for ephemeral Gully incision. Geomorphology, 16, pp. 161-173, 1996.

[14] Poesen, J., Vandaele, K., van Wesemael, B., Gully erosion: importance and model implications. In: Boardman, J., Favis-Mortlock, D., (eds.), Modelling Soil Erosion by Water. NATO ASI Series, Vol I 55, SpringerVerlag, Berlin, 1998.

[15] Vandekerckhove, L., Poesen, J., Oostwoud Wijdenes, D., de Figueiredo, T., Topographical thresholds for ephemeral Gully initiation in intensively cultivated areas of the Mediterranean. Catena, 33, pp. 271-292, 1998.

[16] Begin, Z. B., Schumm, S. A., Instability of alluvial valley floors: a method for its assessment. Transaction of the ASEA, 22, pp. 347-350, 1979.

[17] Vandekerckhove, L., Poesen, J., Oostwoud Wijdenes, D., Nachtergaele, J., Kosmas, C., Roxo, M.J., de Figueiredo, T., Thresholds for Gully initiation and sedimentation in Mediterranean Europe. Earth Surface Processes and Landforms, 25, pp. 1201-1220, 2000.

[18] Julien, P. Y., O' Brien, J. S., Physical properties and mechanics of hyperconcentrated sediment flows. Proc. Specialty Conference on Delineation of Landslides, Flash Flood \& and Debris Flow Hazards in Utah, pp. 260279, 1985.

[19] Chen, L. C., Generalized viscoplastic modelling of Debris Flow. J. Hydraulic Eng., 114, pp. 237-258, 1988.

[20] Takahashi, T., Initiation and flow of various types of Debris Flow. Proc. Second Int. Conf. Debris Flow Hazards Mitigation: Mechanics, Prediction and Assessment, Wieczorek and Naeser (eds.), Balkema, Rotterdam, pp. 15-25, 2000. 
[21] Jan, C.-D., Shen, H. W., Review Dynamic Modelling of Debris Flows. Recent developments on Debris Flows, Armanini, A.., Michiue, M. (eds.), Springer, pp. 93-116, 1997.

[22] Takahashi, T., Debris Flow. Monograph Series of IAHR, Rotterdam, 1991.

[23] Bagnold, R. A., Experiments on a gravity-free dispersion of a large solid spheres in a Newtonian fluid under shear. Proc. R. Soc. London, Ser. A, 225, pp. 49-63, 1954.

[24] Johnson, A. M., Physical processes in geology. Freeman, Cooper \& Company, pp. 431-571, 1970.

[25] Lorenzini G., Mazza N., A rheologic approach to Debris Flow modelling, Water Resources Management II, WIT Press (UK), pp. 355 - 364, 2003.

[26] Lorenzini G., Mazza N., Buckingham's Theorem application to quadratic method description of Debris Flow rheology: comparison of laboratory to calculated data, Journal of Engineering Thermophysics, 12(4), pp. 325 337, 2003.

[27] Lorenzini G., Natural hazards in mountainous environment and theoretical assessments: differences and analogies, Geo-Environment, WIT Press (UK), pp. $113-122,2004$.

[28] Lorenzini G., Validation of a Debris Flow rheological modelling with experimental data, Rivista di Ingegneria Agraria, 4, pp. 29 - 36, 2004.

[29] Savage, S. B., The mechanics of rapid granular flows. Advances in Applied Mechanics, 24, pp. 289-366, 1984.

[30] Savage, S. B., Hutter, K., The motion of a finite mass of granular material down a rough incline. J. Fluid Mechanics, 199, pp. 177-215, 1989.

[31] Smart, G., Jaeggi, M., Sediment transport on steep slopes. Mitteilungen der Versuchsanstalt für Wasserbau, Hydrologie und Glaziologie, ETH Zürich, 64, 1983.

[32] Lanzoni, S., Tubino, M., Rheometric experiments on mature Debris Flows. Proc. of the $25^{\text {th }}$ Congress of IAHR, Session B, pp. 47-54, 1993.

[33] Gregoretti, C., Di Silvio, G., Gradually varied Debris Flow along a slope. Proc. First International Conference Debris Flow Hazards Mitigation: Mechanics, Prediction and Assessment, ASCE, New York, pp. 767-776, 1997.

[34] Davies, T. R., Using hydro science and hydro technical engineering to reduce Debris Flow hazards. Proc. First International Conference Debris Flow Hazards Mitigation: Mechanics, Prediction and Assessment, ASCE, New York, pp. 787-809, 1997.

[35] Hamilton, D., "Velocity profile assessment for Debris Flow hazards", Proc. First International Conference, Debris Flow Hazards Mitigation: Mechanics, Prediction and Assessment, ASCE, New York, pp. 474-483, 1997.

[36] Simoni, A., Innesco e mobilizzazione di Debris Flow: il bacino sperimentale di Acquabona (BL), PhD thesis in Earth Sciences, XI cycle, (kindly provided by Prof. C. Elmi, Dept. of Geology, Univ. of Bologna), 1988 . 